\title{
A JANELA INDISCRETA DA TESTEMUNHA PRIMO LEVI E O FANTÁSTICO PÓS-AUSCHWITZ
}

\section{Anna Basevi UFRJ/CAPES}

RESUMO: Primo Levi, mundialmente conhecido por seu testemunho do campo de extermínio (Se questo è un vomo, 1947) publicou uma coletânea de contos intitulados Histórias naturais onde utiliza os recursos do fantástico para imaginar as consequências paradoxais da racionalidade humana. A narrativa "Borboleta angélica" destaca-se pelos elementos do horror e do drama, relacionados ao tema das experiências genéticas durante o nazismo. 0 interesse deste conto e a sua especificidade pós-Auschwitz reside em alguns aspectos: em primeiro lugar em sua estrutura que reflete a problemática sobre o testemunho; no efeito de incerteza que se produz entorno ao que seria "imaginável" questionando a frágil fronteira entre real, possível e fantástico; a organização narrativa a partir do eixo rastro-fragmento-testemunho. Veremos, desta forma, como o texto é marcado por um dos eventos mais traumáticos do século XX.

PALAVRAS-CHAVE: Auschwitz. Fantástico. Primo Levi.

\section{THE WITNESS INDISCREET WINDOW PRIMO LEVI AND SURREALISM AFTER AUSCHWITZ}

ABSTRACT: Primo Levi, renowned for his testimony of Nazi camp (If This Is a Man, 1947), published a collection of short stories entitled "Natural Tales". He uses the surrealistic elements and plots to imagine the paradoxical consequences of human rationality. "Angelic Butterfly" relates to the theme of genetic experiments during Nazism and stands out for horror elements and drama. This tale's relation to the post-Auschwitz reflection lies firstly in its structure which raises the question of the witness; secondly, in the uncertain effect of the "imaginable" as it questions the fragile boundary between real, possible and fantastic; thirdly in the narrative organization based on the connection of the ideas of trace, fragment and testimony. In my analysis I will expose how this text is marked by one of the most traumatic events of the twentieth century.

KEYWORDS: Auschwitz. Fantastic. Primo Levi. 


\section{A JANELA INDISCRETA DA TESTEMUNHA PRIMO LEVI E O FANTÁSTICO PÓS-AUSCHWITZ}

Anna Basevi

A ruptura que o extermínio nazista trouxe na consciência do mundo ocidental vinculou o conceito de realidade ao trauma, impondo à literatura, como afirma Márcio Seligmann-Silva, a busca de "uma nova concepção de representação que permita a inclusão desse evento" ${ }^{1}$. Giorgio Agamben fala de "lição decisiva do século" e Shoshana Felman de "século pós-traumático" ${ }^{3}$ : o nosso tempo está, portanto, incumbido de redefinir a relação entre o mundo e sua representação, levando em consideração a catástrofe e os paradoxos da modernidade, tarefa pela qual a literatura é convocada como um dos veículos principais. Se a Shoah irrompe com "fatos tão reais, os únicos reais para o sobrevivente e ao mesmo tempo inimagináveis" (segundo a síntese de Agamben ${ }^{4}$ ), como se reconfigura a relação entre real e irreal, possível e impossível na narrativa fantástica após Auschwitz, e principalmente na obra de um escritor-sobrevivente?

\section{EXPERIÊNCIAS INIMAGINÁVEIS}

Mundialmente conhecido por sua primeira publicação, É isto um homem? (Se questo è un uomo, 1947) - uma das obras fundamentais da literatura de testemunho - Primo Levi escreveu, além de outros textos mais conhecidos ${ }^{5}$,

\footnotetext{
${ }^{1}$ SELIGMANN-SILVA, Márcio. A história como trauma. In: NESTROVSKI, Arthur; SELIGMANNSILVA, Márcio (Orgs.). Catástrofe e representação. São Paulo: Escuta, 2000, p. 75.

${ }^{2}$ AGAMBEN, Giorgio. O que resta de Auschwitz. São Paulo: Boitempo, 2008, p. 20.

${ }^{3}$ FELMAN, Shoshana. Educação e crise ou as vicissitudes do ensinar. In NESTROVSKI, Arthur; SELIGMANN-SILVA, Márcio (Orgs.). Catástrofe e representação, op. cit., p. 13.

${ }^{4}$ AGAMBEN, Giorgio. O que resta de Auschwitz, op. cit., p. 20

${ }^{5}$ Os outros títulos célebres são as narrativas autobiográficas, A trégua (La tregua, 1963) e A tabela periódica (Il sistema periodico, 1975), e o ensaio e última obra, Os afogados e os sobreviventes (I sommersi e i salvati, 1986). Levi escreveu também os romances $A$ chave estrela (La chiave a stella, 1978) e Se não agora, quando? (Se non ora, quando?, 1982), poesias, textos narrativo-ensaísticos, artigos e numerosos contos com temas diversos. Apesar de suas declarações sobre a marginalidade da atividade de escritor em relação à atuante profissão de químico, Levi é hoje considerado um "clássico" da literatura do século XX, continuamente reeditado e o autor moderno mais lido nas escolas italianas.
} 
uma coletânea de contos intitulada Storie naturali (1966), hoje traduzida para o português e publicada em uma coletânea maior chamada 71 contos de Primo Levi ${ }^{6}$. Nos contos de Histórias naturais, o escritor utiliza, como já outros fizeram, os recursos do fantástico para imaginar as consequências aporéticas e extremas da racionalidade humana, a qual, através de uma inquietante combinação de audácia científica e falta de escrúpulos éticos, consegue produzir resultados "inimagináveis". Embora a crítica não tenha um juízo unânime sobre os numerosos contos de Levi (enquanto é hoje unânime a consagração de Levi e de É isto um homem? como obra de alto valor literário), é recente a curadoria por Ernesto Ferrero de uma reedição de alguns contos protagonizados por animais sob o título Ranocchi sulla luna e altri racconti (Rãs na lua e outros contos). Segundo Ferrero, as narrativas breves escritas entre as décadas de 50 e 70, são "apólogos", "exempla" nos quais é central algum questionamento moral ${ }^{7}$; ao mesmo tempo, o cenário de uma gênese interminável quase em direta competição com Deus, habitado por cientistas, seres e situações extraordinários, é recorrente em Levi como o sonho humano de construir "uma espécie de laboratório semiclandestino, sempre aberto, onde sua paixão artesanal (o 'pensar com as mãos' que tanto lhe agrada) permite farejar cruzamentos poderosos". ${ }^{8}$ Do ponto de vista estilístico, Ítalo Calvino, amigo e estimador de Levi, elogiava este "mecanismo fantástico que parte de um dado científico-genético" pela sua força intelectual e poética, pelo humorismo e equilíbrio narrativos presentes ${ }^{9}$ enquanto Marco Belpoliti - organizador da obra completa de Levi e da edição da coletânea completa de contos $^{10}$ -, ressalta a familiaridade com o gênero da paródia, privilegiado por um dos autores mais estimados pelo próprio escritor, François Rabelais. Se nem todos os contos de ficção científica ou de sociedades imaginárias obtêm um resultado uniforme de eficácia narrativa, "Borboleta angélica" pertence à produção do escritor capaz de suscitar um ponto de vista crítico a partir de sua qualidade.

Na produção fantástica de Levi, geralmente caracterizada por um tom

\footnotetext{
${ }^{6}$ LEVI, Primo. 71 contos. Trad. Maurício Santana. São Paulo: Companhia das Letras, 2005.

7 FERRERO, Ernesto. Introduzione. In: LEVI, Primo. Ranocchi sulla luna e altri animali. A cura di Ernesto Ferrero. Torino: Einaudi, 2014, p. X.

8 Ibidem, p. XIX.

${ }^{9}$ CALVINO, Ítalo apud ibidem, p. IX.

${ }^{10}$ Marco Belpoliti é também autor do mais recente ensaio crítico de 700 páginas, Primo Levi di fronte e di profilo, lançado no final de agosto de 2015 na Itália pela editora Guanda.
} 
irônico, por vezes fruto de uma visão crítica do presente, outras vezes inspirado por uma inquietação sobre o futuro, mas raramente trágico, o conto "Borboleta angélica" destaca-se pelos elementos do horror e do drama explícito, relacionados ao tema da obsessão genética do nazismo.

O interesse do texto e a sua especificidade pós-Auschwitz residem, a nosso ver, em determinados aspectos narrativos: em primeiro lugar em sua estrutura, capaz de refletir a temática; em seguida, no efeito de incerteza que se produz entorno ao que seria "imaginável". Para desenvolver nossa reflexão é preciso ressaltar três momentos que, ao longo da trama, correspondem a três cenas diferentes; representam também as três etapas da reconstrução de um caso estranho onde no começo há apenas indícios a serem coletados, sem o conhecimento do tipo de crime ocorrido. Veremos porque a terceira e última parte caracteriza o texto como marcado pelo evento sintetizado no nome-emblema de Auschwitz.

A breve narrativa inicia-se com a cena que reúne quatro membros de uma comissão internacional, dois meses depois do fim da Guerra, em 1945, na cidade de Berlim ainda ocupada pelas Forças Aliadas. Um francês, um inglês, um americano e um russo são encarregados de colher indícios, vestígios, sinais e eventuais testemunhos para descobrir o que acontecera, durante o conflito, numa habitação concedida a um pesquisador alemão, tal professor Leeb, do qual nada mais se sabe. Nesta primeira fase de perlustração no apartamento, os homens encontram materiais variados: cascas, panos imundos, penas e excrementos de pássaros, ossos, e repugnantes restos infestados de vermes. Diante de um espetáculo tão desolado o russo exclama com desprezo: "Herrenvolk!", expressão não traduzida no texto, mas que significa "povo dos senhores" e utilizada pelo nazismo com o sentido de raça superior. Por meio de uma junção irônica o discurso equipara, portanto, vermes e a raça superior, antecipando a imagem dantesca das borboletas geradas dos "vermes" página sucessiva repete-se a conexão entre os desagradáveis vestígios e o nazismo quando o químico encarregado pela análise das amostras se queixa dos "restos nojentos" e conclui: "sangue, cimento, xixi de gato, e de rato, chucrute, cerveja: ou seja, a quintessência da Alemanha". O grupo consegue enfim deter uma jovem disponível a testemunhar, mas nós leitores não a escutamos logo - isto é, não lemos neste momento sua fala - , pois há um

${ }^{11}$ Ver nota n. 12. 
corte e a narração segue com uma segunda cena. Aqui o coronel responsável pela investigação janta com os quatro homens do início, mais outros colaboradores (cientistas, jornalista etc.) e aproveita para explicar o fenômeno reprodutivo da neotenia dando como exemplo a espécie do axolotl, uma salamandra mexicana que costuma se reproduzir ainda no estado de larva, antes de virar adulta. Estes conhecimentos zoológicos, segundo a explicação do coronel, teriam estimulado as ousadas experiências do professor Leeb na tentativa de extrair do ser humano um ser superior. O narrador intervém para acrescentar mais um indício em favor do conhecimento do leitor sobre a personalidade de Leeb: descobrimos que o cientista alemão interessava-se nos textos $O$ mito do século $X X$ de Alfred Rosenberg, teorizador de ideias racistas, e o Purgatório de Dante. Aprendemos assim, em parte, a razão do título "Borboleta Angélica", derivada do décimo canto do Purgatório onde, ao comparar a alma a uma borboleta, um espírito sugere a Dante a possibilidade de metamorfose do corpo humano após a morte. Nós mortais somos, diz o verso dantesco, vermes nascidos para formar a angelical borboleta, onde a similitude associa a alma à borboleta que renasce do corpo-verme. ${ }^{12}$

O leitor começa a conectar a sensação inquietante dos indícios da primeira imagem (a casa abandonada com restos) à personagem de Leeb e às suas teorias sobre o desenvolvimento do potencial angelical dos seres humanos (a segunda etapa). Mas até aqui, nós leitores temos apenas fragmentos de informações, oferecidas nas duas cenas da casa e do jantar, que não costurariam o episódio se não houvesse a terceira parte da narração: o testemunho, ou melhor, fragmentos de testemunho, porém decisivos, de uma garota de 19 anos, a qual três anos antes observara de sua janela alguns movimentos estranhos na casa da frente, justamente a casa do mistério. Ouvimos finalmente a testemunha relatar o que havia espiado (e sua narração também se refere a momentos temporais diversos). A primeira vez, ela viu dois homens e duas mulheres levados na habitação. As portas e janelas daquela casa, sempre trancada, vão assim se abrindo aos poucos pela narração. Mais uma informação é acrescentada com outro episódio: de repente um bombardeio ajudara a curiosidade da menina quando destruiu os vidros da janela da casa de Leeb.

\footnotetext{
${ }^{12}$ ALIGHIERI, Dante. Canto X. Purgatório. In: A Divina Comédia. São Paulo: Editora 34, 2008, v.124. "O superbi cristian, miseri lassi, /che, de la vista de la mente infermi, /fidanza avete ne' retrosi passi,/ non v'accorgete voi che noi siam vermi / nati a formar l'angelica farfalla,/ che vola a la giustizia sanza schermi?" (vv. 121-126).
} 
Ela conta, portanto, ter descoberto naquela ocasião (e sempre pela sua janela) um enfermeiro que vigilava enquanto os quatro estavam deitados e inertes, condição, esta, que evidentemente não lhes permitiu ouvir os bombardeios (estariam vivos ou mortos?); dias mais tarde e graças a um segundo bombardeio, ela conseguiu observar melhor o interno da casa onde desta vez se debatiam, acorrentadas, quatro horrendas aves parecidas a urubus com pequenas asas sem penas, e com cabeças de múmias. Os fragmentos de visões até aqui recolhidos juntam-se a mais um episódio presenciado assim que terminara a guerra. Ela segue narrando: àquela altura todas as pessoas, desesperadas e famintas, moravam na rua após a destruição de suas casas, enquanto a casa do professor Leeb permanecera em pé. Ao notar uma multidão barulhenta e agitada entrando e saindo da habitação, a menina aproximou-se e descobriu que as pessoas haviam atacado as aves para uma macabra refeição, todos ignorando (ela inclusive) a proveniência das infelizes criaturas. Somos nós leitores que podemos enfim reconstruir o caso e adivinhar o nexo entre as cenas entreolhadas. Desvela-se a tentativa do doutor Leeb de extrair do corpo humano criaturas puras obtendo um resultado oposto e assombrado: quatro monstros destinados a um terrível final. A potencialidade pertencente ao imaginário dantesco é aqui invertida numa metamorfose negativa que denuncia a ausência de qualquer forma angelical no ser humano e demonstra a outra face, tenebrosa, de todo mito de pureza. Estamos num mundo revirado: imagem e expressão, esta do mundo revirado, frequente na narração de Levi sobre o campo de extermínio, assim como de cabeça para baixo é o desenho piramidal do Inferno de Dante - um dos grandes intertextos da obra de escritor.

Do nosso ponto de vista, não se trata apenas de ressaltar a alegoria das experiências de alteração genética e uma visão apocalíptica — ou seja, o tema - mas de perceber a instabilidade da fronteira entre o possível e o inacreditável, organizadora da narrativa. Os fatos são reconstruídos através de bizarros indícios e trechos de histórias, informações reais e estranhas ao mesmo tempo, que parecem fantásticas como o esquisito axolotl ou o não muito conhecido fenômeno da neotenia, (segundo o qual seres adultos de alguma espécie mantêm características morfológicas e fisiológicas típicas de estádios juvenis anteriores). Por outro lado, surge um estranhamento: temos uma narração onde quase tudo é verossímil menos a metamorfose de pessoas em inquietantes pássaros; no entanto a sensação que a leitura suscita é uma incerteza 
contínua sobre a fronteira entre real e irreal. Tanto o fenômeno da neotenia quanto o axolotl estão alinhados com outros frutos da fantasia de Levi, como frequentemente acontece em seus contos fantásticos, onde sua experiência de cientista lhe permite criar nomes, animais, teorias, sempre na fronteira entre o real e a invenção para o gênero textual da ficção científica. A primeira impressão do leitor é, portanto, de estar na dimensão imaginária dentro da qual Levi pode ter criado um fenômeno e sua terminologia técnica; se na dúvida, porém, o leitor digitar as palavras desconhecidas na "rede", fotos como as seguintes aparecerão, com todas as explicações:
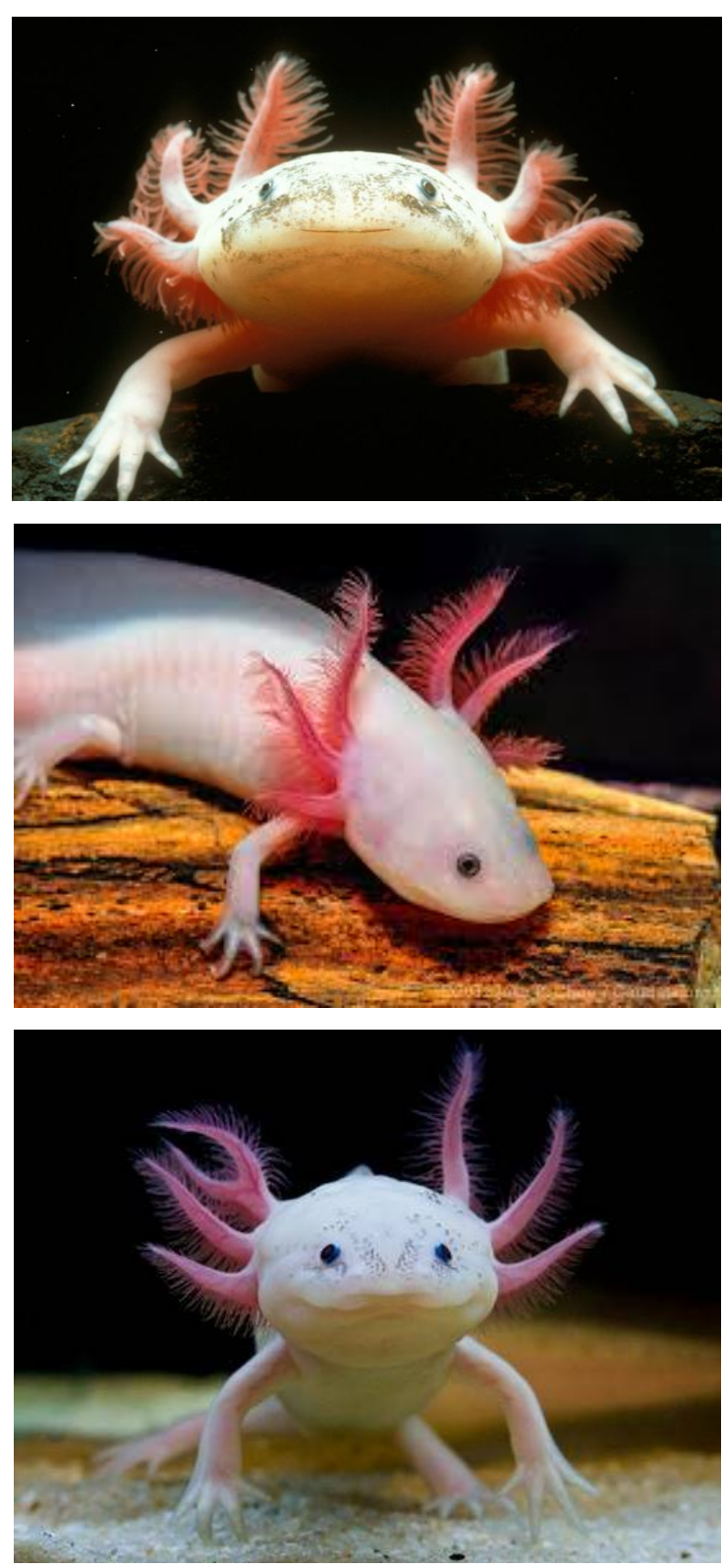
Desnorteados, não sabemos mais o que é fantasia e o que realidade, pois estas imagens parecem mais falsas do que verdadeiras e as criaturas fotografadas transmitem algo inquietante. A este ponto instala-se uma dúvida sobre os conteúdos do texto: talvez a metamorfose em aves narrada seja possível enquanto o axolotl pode ser uma brincadeira no mundo da informação em rede; ou os dois fenômenos estão ambos na ordem do extraordinariamente real?

Uma sensação entre surpresa, confusão e terror ocorreu em outro tipo de estranhamento experimentado em Auschwitz, principalmente no primeiro impacto, relatado em É isto um homem? por meio da descrição de um mundo não interpretável e estados de ânimo de desarmada incredulidade:

absurda precisão (p. 14); desconcertados e desarmados (p. 18); incompreensível e louco (p. 19); agora é o segundo ato (p. 21); tudo isto é apenas um enorme aparato para caçoar de nós (p. 22); parece-nos assistir a alguma peça maluca (p. 23); coisas estranhas e absurdas (p. 23); atônitos e transtornados (p. 24); infindáveis e insensatos são os rituais obrigatórios (p. 32); frente a este complicado mundo infernal, minhas ideias se confundem (p. 40); geométrica loucura (p. 50); hoje eu mesmo não estou certo de que esses fatos tenham realmente acontecido (p. 105). ${ }^{13}$

Retomaremos, então, a pergunta inicial, gerada pelo efeito da narrativa: se houve na esfera dos fatos históricos, chamados "reais", algo inimaginável, onde estaria o limite, a capacidade de prever e definir o que é possível e o que é impossível? Em outros termos, se Auschwitz foi possível, haveria outras irrealidades prestes a se tornarem reais? Por quais metamorfoses devemos esperar na oscilação imprevisível entre humano e inumano? A experiência do inimaginável (e espantoso, pois acreditamos nele como se acredita na cena sonhada de um pesadelo) perpassa todo o conto "Borboleta angélica" em gradações e dimensões diversas: a pureza da raça que leva às câmaras de gás (nível da História), as experiências delirantes do doutor Leeb (nível da trama), nossa confusão sobre real e fantástico (nível do efeito da leitura). Se já percebemos como desestabilizadora a ausência de critérios para saber se o impossível se tornará real e se o possível atingirá o inimaginável, o que produz o curto circuito na leitura é a consciência traumatizada de que algo chamado

\footnotetext{
${ }^{13}$ As referências das páginas são aqui relativas à edição brasileira: LEVI, Primo. É isto um homem? Trad. Luigi Del Re. Rio de Janeiro: Rocco, 1988.
} 
Auschwitz aconteceu.

Para frisar a irrealidade do real e a realidade do irreal, vale a pena lembrar que a referência ao texto de Alfred Rosenberg, $O$ mito do século $X X$ (Der Mythus des 20. Jahrhunderts, 1930) remete a uma longa série de pensadores e divulgadores das ideias nazistas que orbitam em torno da eugenia ${ }^{14}$ e das técnicas adotadas em prol da suposta superioridade racial. Embora uma eugenia de tipo "preventivo" tenha surgido, de fato, no início do sec. XX em muitos países (Suíça, EUA, Dinamarca, Suécia), sob influência das concepções positivistas, como convicção de que a esterilização de pessoas fisicamente ou psiquicamente doentes fosse uma proteção social e um direito do Estado, esta foi também a porta de entrada da política genética do regime nazista que desenvolveu, poucos anos depois das leis sobre esterilização, teorias para a eliminação física dos sujeitos considerados imperfeitos. No livro-manifesto Mein Kampf de 1925, Adolf Hitler já propõe explicitamente o que virá a ser o centro do plano "Aktion T-4", isto é a eliminação de pacientes psiquiátricos ou pessoas com deficiências físicas ou psíquicas que será realizado entre 1939 e 1941. ${ }^{15}$

Se as ideias de superioridade racial de alguns povos europeus e, mais especificamente, nórdicos, são sustentadas por vários pensadores ao longo das décadas do novo século, a Alemanha hitleriana implementa uma política sistemática e institucional, desde a primeira cadeira acadêmica da disciplina "Higiene da raça" concedida a Fritz Lenz à propaganda liderada pelo teórico oficial Hans F.K. Günther, até as criminosas experiências com seres humanos vivos (principalmente ciganos e judeus) realizadas por Robert Ritter e Josef Mengele.

De outro lado, a organização do projeto Lebensborn por parte do braço direito de Hitler, Heinrich Himmler, representa a outra face do racismo nazista, pois se os projetos de eutanásia e da Endlösung der Judenfrage (a "solução

\footnotetext{
${ }^{14} \mathrm{O}$ conceito de "eugenia" (palavra criada por Francis Galton, primo de Darwin, em 1883) surge numa época na qual as elites ocidentais e positivistas, partindo das bases darwinianas e malthusianas sobre evolução, estão interessadas no aperfeiçoamento genético da espécie humana e inevitavelmente desemboca no desenvolvimento de classificações mais políticas do que científicas das assim ditas "raças" humanas.

${ }^{15}$ Para uma abordagem histórica destas questões: FRIEDLANDER Henri. Le origini del genocidio nazista. Dall'eutanasia alla soluzione finale. Trad. Massimo Maraffa. Roma: Editori Riuniti, 1997. [The Origins of Nazi Genocide, Chapel Hill, 1995]; KOHN, Marek. The Race Gallery. The Return of Racial Science. London: Vintage, 1996; MÜLLER-HILL, Benno. Scienza di morte. L'eliminazione degli ebrei, degli Zigani e dei malati di mente 1933-1945. Trad. Italo Barrai. Pisa: ETS editrice, 1988. [Tödliche Wissenschaft, Hamburg, 1984].
} 
final da questão judaica") visam eliminar aqueles considerados indignos de viver, com a seleção atuada no Lebensborn - e a assistência oferecida as mães envolvidas no programa - pretendia-se favorecer o nascimento dos loiros filhos da "raça ariana" e desta forma elevar o grau de "pureza" do sangue e das feições consideradas germânicas. O que de fato se constata é que antropólogos, médicos, cientistas e psiquiatras colaboraram à estruturação de uma justificativa para o extermínio e para a utilização de seres humanos a ele destinados, por um lado e, por outro, constroem um idealismo de pureza que se aproxima do monstruoso.

Pode-se entender, portanto, o comentário de Primo Levi sobre sua produção fantástica incluindo perfeitamente o conto em questão: "Estas histórias são mais possíveis do que outras".

\section{JANELA INDISCRETA}

Acenaremos a outros elementos concernentes à imagem da garota que espiava pela janela de escondido enquanto ouvia do pai a afirmação: "nós, alemães, menos sabemos, melhor será". Em primeiro lugar, a partir deste discurso, o autor inscreve a monstruosa inversão metamórfica no contexto de uma Alemanha cúmplice e muda por indiferença ou medo. Além disso, a testemunha, apesar de central na narração e na resolução do caso, é colocada fisicamente à margem do cenário (a janela), confirmando, por um lado, o lugar privilegiado de observação do escritor e, por outro lado, a condição necessária, mas incompleta, de quem testemunha no lugar das vítimas. Ressaltaremos que as janelas são duas, com um espaço intermediário vazio de um mundo mudo/surdo/cego.

Segundo a reflexão desenvolvida no ensaio Os afogados e os sobreviventes, o testemunho "integral" pertenceria aos que desapareceram nas câmaras de gás e não podem mais narrar a destruição até suas etapas finais.

Não somos nós, os sobreviventes, as autênticas testemunhas. [...] Nós sobreviventes somos uma minoria anômala além de exígua: somos aqueles que, por prevaricação, habilidade ou sorte, não tocamos o fundo. Quem o fez, quem fitou a Górgona, não voltou para contar, ou voltou mudo; mas são eles, os "muçulmanos", os que submergiram - são eles as testemunhas integrais, cujo depoimento teria um significado geral. ${ }^{16}$

\footnotetext{
${ }^{16}$ LEVI, Primo. Os afogados e os sobreviventes. São Paulo: Paz e terra, 2004, p. 81; p.72.
} 
A condição do sobrevivente incumbido pela tarefa tanto urgente quanto limitada de dar voz às "verdadeiras" e mudas testemunhas é retomada por Agamben e definida "paradoxo de Levi" em O que resta de Auschwitz. ${ }^{17}$

Como acenado acima, não indiferente permanece a posição decisiva e ao mesmo tempo deslocada da testemunha, no umbral constituído pela janela de onde tenta compreender os acontecimentos atravessando a barreira da outra janela. Se as paredes e a janela da casa muda formam a fronteira mortal entre o mundo de dentro e de fora como metáfora do arame farpado dos campos de concentração ou o portal a um mundo infernal, o lugar do umbral de onde se espia o crime não opera como distanciamento e cegueira perante os acontecimentos, mas, ao contrário, auxilia a obstinação de um olhar curioso, engajado na exploração do horror semiescondido e tolerado pela maioria. É preciso sublinhar que a imagem do umbral não é rara na obra do escritor e remete à sua ideia de escrita testemunhal. Além da questão já citada da relatividade ontológica do testemunho (segundo o escritor, não existe uma "testemunha integral" e o testemunho possível é incompleto), Levi também escolhe uma perspectiva mais subjetiva do que panorâmica, porque literária e não histórica, já desde sua estreia como escritor. Sobre a presença frequentíssima do ponto de vista tomado a partir de uma abertura ou de uma porta, Alberto Cavaglion afirma que o ato de se colocar no umbral sintetiza de maneira insuperável o estilo de Primo Levi, "sua modalidade de observar o Mal 'na soleira"'18. A colocação "de seu olhar de juiz" neste espaço fronteiriço representa também uma escolha de moderação, como ainda observa Cavaglion ${ }^{19}$ referindo-se ao simbolismo de sua "posição intermediária, nem externa nem interna" em É isto um homem?. O testemunho de Levi, de fato, propõe um discurso sobre os campos de extermínio - e, portanto, desafia o silêncio - mas sua fala distancia-se da descrição enfática e chocante. Segundo o crítico, o escritor evita "os tons extremos do grito e da mudez" ${ }^{20}$ na escolha de seu estilo narrativo: "O indizível não tem lugar no livro: é a percepção de quem, após ter

\footnotetext{
${ }^{17}$ AGAMBEN, Giorgio. O que resta de Auschwitz, op. cit., p. 151.

${ }^{18}$ CAVAGLION, Alberto. Il senso dell'arca, Ebrei senza saperlo. Nuove riflessioni. Napoli: L'ancora, 2006, p.79

${ }^{19}$ Alberto Cavaglion, um dos críticos mais atentos à obra de Levi, organizou a última edição italiana de Se questo è un uomo, enriquecendo-a com oitenta páginas de relevantes notas e comentários colocados no final, mais uma breve apresentação inicial. LEVI, Primo. Se questo è un uomo. Edizione commentata a cura di Alberto Cavaglion. Torino: Einaudi, 2012. Notas p. 153-237.

${ }^{20}$ CAVAGLION, Alberto. Il senso dell'arca, Ebrei senza saperlo, op. cit., nota p. 153.
} 
estado 'no umbral da casa dos mortos', dela entreviu os traços, mas entendeu que a salvação poderá advir somente da escrita." ${ }^{21}$

A condição da testemunha entre duas posições-limites reafirma, portanto, a preferência por um tom de voz moderado, e ao mesmo tempo permanece sendo o alicerce da narração: aumenta-se não o volume, mas a potência da palavra dita. Assim é também no caso da jovem espectadora da metamorfose do humano em in-(h)umano.

Evidentemente, no coração da interpretação proposta encontra-se a questão relevante da função testemunhal. Na própria construção do texto, o que torna os fragmentos parte de uma trama com um sentido é exatamente o relato da jovem testemunha, pois este permite desvelar um episódio escondido e terrível que nenhuma personagem presenciou completamente. Como vimos, o episódio acontecido em um quarto trancado remete à problemática da falta de testemunha integral, aquela que não voltou de sua morte para testemunhar, pois a testemunha integral corresponderia a uma das quatro cobaias do Dr. Leeb. Coerentemente, ao longo da trama, não temos um testemunho completo, e sim fragmentos de discursos e visões. Assim, os fragmentos de materiais recolhidos pelas personagens perplexas e enojadas refletem os fragmentos narrativos com os quais nos deparamos e que precisamos recompor no final na nossa tarefa de leitores. O procedimento não teria, porém, nada de original se tudo isso se limitasse a um mosaico, a uma recomposição de fragmentos narrativos rumo a uma decodificação textual; no entanto, a linha que costura e organiza o encaixe final é dada justamente pelo aspecto testemunhal de um evento inimaginável, capaz afinal de recuperar o terrível fato escondido.

No Brasil, é de Renato Lessa a proposta de ler os textos do escritor italiano como um "proceder em fragmentos", como uma experiência reconstituída através de fragmentos ${ }^{22}$, e de fato toda a prosa de Levi se caracteriza por sintéticas e densas descrições de personagens e múltiplas micro-estórias inseridas na trama. Lessa identifica no que ele chama "a estética do fragmento" a

\footnotetext{
${ }^{21}$ Ibidem, Presentazione, p. XI. A expressão "no umbral da casa dos mortos", de influência dostoievskiana, é de Levi. Cf. tradução brasileira: "Nunca mais vi Schlome, mas não esqueci seu rosto sério e suave de criança, que me recebeu no umbral da casa dos mortos" (p. 29). A partir deste episódio, Alberto Cavaglion foi quem desenvolveu primeiro a análise intertextual com a obra de Dostoievski.

${ }^{22}$ LESSA, Renato. O silêncio e sua representação. In: SCHWEIDSON, Edelyn. Memória e cinzas. Vozes do silêncio. Rio de Janeiro: Ed. Perspectiva, 2009, p. 96-97.
} 
modulação possível do testemunho de algo impossível de se transmitir e, em geral, da narrativa pós-Auschwitz.

Além da figura do fragmento, outra imagem operacional nos ajuda na leitura do texto: a metáfora do rastro que Jeanne Marie Gagnebin retoma a partir de Paul Ricoeur. A aporia da "presença do ausente e a ausência da presença" contida na metáfora "preciosa" e "complexa" do rastro ${ }^{23}$ permite "superar, apesar da ambivalência da presença de algo que não mais existe, o silêncio definitivo que se instauraria sem o texto escrito". Se Jean-Pierre Vernant observa que a palavra grega séma tem como significação originária a de "túmulo" e, só depois, a de "signo", Gagnebin ressalta a natureza comum dos diferentes rastros, o túmulo, o signo, a palavra, a escrita como veículos de rememoração e luta contra o esquecimento. ${ }^{24} \mathrm{O}$ rastro se torna, então, uma sorta de interface do testemunho. No conto estudado, os rastros encontrados na habitação e o testemunho final da jovem se completam e se comprovam mutuamente, e mutuamente restituem um sentido um ao outro dando uma direção e uma forma final à narração.

O tradutor da edição brasileira dos contos, Maurício Santana Dias, conclui que "o campo da invenção remete o escritor à hipótese aberrante de que talvez a espécie esteja orientada para a autodestruição" ${ }^{25}$, mais do que pode transparecer de seus livros testemunhais. Em muitas de suas breves narrativas Levi "deixou que viessem à tona, sob formas desimportantes, os destroços daquele naufrágio" ${ }^{26}$. Se o nosso tempo caracteriza-se como "era das testemunhas", segundo a definição da historiadora Annette Wieviorka ${ }^{27}$, podemos sem dúvida ler o conto em questão, sobre rastros e testemunho, ele mesmo como rastro e testemunho da catástrofe na literatura fantástica. Em "Borboleta angélica" o eixo entre rastro, testemunho e o olhar da testemunha central/deslocado representam o núcleo narrativo marcado pelo evento traumático do século $X X$.

${ }^{23}$ GAGNEBIN, Jeanne Marie. O rastro e a cicatriz: metáforas da memória. In: Lembrar escrever esquecer. São Paulo: Editora 34, 2009, p.44. Ver também p.107-118 e o ensaio: Verdade e memória do passado, Ibidem, p. 39-47.

${ }^{24}$ Idem, O rastro e a cicatriz, op. cit., p. 112.

${ }^{25}$ SANTANA DIAS, Maurício. Primo Levi e o zoológico humano. In: LEVI, Primo. 71 contos, op.cit. p. 9-20.

${ }^{26} \mathrm{Ibidem}$

${ }^{27}$ WIEVIORKA, Annette. L'era del testimone. Milano: Raffaello Cortina, 1999. [L'ère du témoin. Paris: Fayard, 2013. 1. ed. 1998] 